\title{
Franquismo y educación. Relato de los silenciados
}

\author{
Nazaret Martínez Heredia. Universidad de Granada \\ Alena Kárpava. Universidad Nacional de Educación, UNAE (Cañar, Ecuador)
}

Recepción: 20 de junio de 2016 | Revisión: 30 de junio de 2016 | Aceptado: 12 julio de 2016

Correspondencia: nazareth@ugr.es | alena.karpava@unae.edu.ec

Citar: Martinez-Heredia, N. y Karpava, A. (2016). Franquismo y educación. Relato de los silenciados. ReiDoCrea, 5, $166-176$.

Resumen: La posguerra constituyó una etapa muy dura dentro de la historia de España, caracterizada por la carencia económica ligada a un empobrecimiento de la población junto con el desarrollo del temor y la desorganización vivida en la primera etapa del franquismo. El objetivo de este estudio es conocer las características del sistema educativo y de la escuela como centro físico correspondiente a la Época Franquista y averiguar si la asistencia a la escuela estaba condicionada por el nivel económico de las familias. Este intento nos llevó a la construcción de historias de vida en un pequeño pueblo de la provincia de Granada, enmarcada en una metodología cualitativa, empleando la entrevista semiestructurada y en profundidad. El análisis de contenido de la entrevista realizada nos permitió, a través de la narración de nuestros informantes, profundizar en las características de su escolarización apreciando la gran carencia económica y educativa derivada de la situación posbélica y de sus posteriores consecuencias. Del mismo modo, nos permitió conocer la educación impartida y las grandes diferencias existentes, tanto en la vida cotidiana, como en la escolarización de dicha época, compartiendo con nuestro entrevistado momentos muy íntimos regalándonos la posibilidad de conocer elementos muy personales de momentos vividos junto a familiares y amigos.

Palabras clave: Historia oral | Educación

Education in the Franco years. The story of the silenced

\begin{abstract}
The postwar period was a very difficult stage in the history of Spain, characterized by economic deprivation tied to the impoverishment of the population with the development of fear and disruption experienced in the first part of the Franco Epoch. The aim of this study is to understand the characteristics of the education system and of the school as a physical center corresponding to the Franco Epoch and to determine if the economic level of families conditioned school attendance. This intention led us to the construction of life stories in a small village in the province of Granada, framed in a qualitative methodology using a semi-structured and in-depth interview. The analysis of the content of the interview allowed us, through the story of our informants, to gain a deeper understanding of the characteristics of their schooling and to discern the great economic and educational deficiency resulting from the post-war situation and its aftermath. Similarly, we were able to understand the education received and the great differences in everyday life and in the education of that time, sharing with our interviewee very intimate moments that provided the opportunity to learn about personal elements of moments spent with family and friends.
\end{abstract}

Keywords: Oral History | Education

\section{Introducción}

La posguerra constituyó una etapa muy dura dentro de la historia de España, caracterizada por la carencia económica ligada a un empobrecimiento de la población junto con el desarrollo del temor y la desorganización vivida en la primera etapa del franquismo (Puelles, 2008). Durante esta etapa las carencias en el sistema económico del país provocó una tasa de analfabetismo en torno al $50 \%$, el número de escuelas era prácticamente precario, poniendo de manifiesto el presupuesto insuficiente dedicado a la instrucción pública y la precariedad del sueldo de los maestros (Lucena, 1999).

No podemos obviar el papel social, político, económico, moral de la iglesia durante la primera etapa del régimen franquista, cuyo dominio reflejan los textos escolares de mediados del siglo XX. El contenido de estos textos recaía, en su mayor parte, sobre la importancia de la enseñanza de la moral, vinculada al dogma católico y derecho de la iglesia de intervenir en el proceso educativo de los centros. En las escuelas se conservaron textos religiosos, que ilustra la incorporación de la Religión en la enseñanza, que promulga el respeto hacia la moral y el dogma católico, junto con el derecho de la iglesia a realizar inspecciones dentro de los centros educativos. 
La segunda etapa del franquismo comienza con el cierre de una importante época política, caracterizada por una grave crisis económica, alto nivel de analfabetismo y un gran estancamiento de la escuela pública. Puelles (2008) describe el éxito que tuvo la incorporación del Plan de Estabilización Económica de 1959 en este período histórico, que dio el inicio al crecimiento económico que, a su vez, generó el desarrollo industrial. La educación en este momento estaba sometida a un importante proceso de modernización. La preferencia se daba a los valores de eficacia, eficiencia, productividad y crecimiento económico de la sociedad.

Por otro lado, diversos autores como Redondo Morcillo o Peralta Ortiz, recogen la importancia que tenían en esta época el aprendizaje de la lectura y la escritura dentro del aula, eje central del currículum de la Escuela Primaria en los años 60. También habría que destacar el papel de la escuela en la delimitación de los roles socioculturales atribuidos a un determinado sexo. Así Rabazas y Ramos (2006) resaltan que a la mujer se le asignaba el papel educador, mientras al varón se le atribuía el poder de ser sustento económico de la familia. La educación de ambos sexos estaba marcada por los valores de la obediencia, amistad, respeto hacia los demás y el impulso de la oración.

Según Sánchez Redondo (2004), las instituciones educativas en la época franquista se caracterizaban por su carácter segregador, ya que la escuela mixta y la coeducación estaban totalmente prohibidas. El modelo educativo de aquel entonces diferenciaba el currículum académico en función al género. El contenido en los colegios femeninos respondía a las necesidades del hogar y la familia y fue marcado por los temas centrados en las labores y economía domésticas (microeconomía), enfermería, confesión de ropa, bordado, educación de los hijos, etc. En el caso de los centros masculinos, las asignaturas integraban conocimientos de carácter científico, macroeconómico, de oficio, centrando en las necesidades de manutención de la familia.

Anteriormente hemos intentado profundizar en el estudio de la educación en la Época Franquista, a través de este trabajo pretendíamos dar a conocer diversos testimonios y vivencias educativas durante el desarrollo de la Época Franquista en el municipio de Zújar. Su experiencia nos llevó a descubrir procesos educativos vividos por muchas personas "simples".

No podemos olvidar que la producción bibliográfica con mayores se trata de un proceso en vías de construcción que poco a poco va tomando fuerza dentro de nuestras investigaciones sociales, por otro lado creemos de especial relevancia conocer la memoria del alumno dentro de la educación centrando nuestra atención en las condiciones socioeconómicas, descripción de la escuela, actividades desarrolladas... pero esta vez desde el punto de vista del educando.

El texto del presente artículo comprende cuatro apartados. El apartado uno integra la justificación del problema. El segundo refleja la metodología utilizada. El tercero recoge la transliteración de los resultados de las entrevistas realizadas, que rescatan la voz de los silenciados a través de un discurso biográfico. El apartado final recoge las conclusiones.

\section{Método}

Nuestro trabajo fue realizado recurriendo a la metodología cualitativa, la historia de vida. Como herramienta de nuestro trabajo empleamos la entrevista semiestructurada y en profundidad caracterizada por ser un modelo del Catedrático de la Universidad de Valladolid, Agustín Escolano García. Hemos recurrido a la investigación cualitativa, 
concretamente la historia de vida, haciendo especial uso de la entrevista semiestructurada y en profundidad. Siguiendo la línea de Escolano y Hernández (2002) la historia de vida nos ofrece una información minuciosa y detallada de la realidad, los sentimientos y las emociones personales de los entrevistados. La metodología de historia de vida nos ayuda a conocer el impacto real de los momentos de cambio y la complejidad de lo vivido de los entrevistados durante el proceso educativo de la época franquista.

Habría que destacar que se trata de una tarea larga, lenta y compleja que nos ayuda a reafirmar o contrastar los objetivos específicos planteados:

- Conocer las características del sistema educativo y de la escuela como centro físico correspondiente a la Época Franquista.

- Averiguar si la asistencia a la escuela estaba condicionada por el nivel económico de las familias.

La metodología de historia de vida proporciona nueva información que ayuda a comprender mejor el problema de la investigación (López Noguero y Pozo Llorente, 2002). Como herramienta de recogida de datos habíamos empleado la entrevista semiestructurada, y en profundidad. Dichas entrevistas se centraban en los siguientes bloques: 1) datos socioeconómicos y personales; 2) datos relacionados con la infancia acerca de los juegos, la vestimenta o la alimentación de la época; 3) contextos y relaciones familiares (miembros que componían la familia, sus estudios y trabajos, relación existente entre los padres y hermanos); 4) características del maestro; 5) horario de la jornada lectiva; 6) características de la escuela como es la estructura del espacio escolar; 7) currículum y metodología empleada; 8) materiales didácticos y libros empleados; 9) actividades extraescolares desarrolladas; 10) actividades del alumnos; 11) método de evaluación. Destacamos la existencia de once categorías para recabar la información necesaria para desarrollar nuestro análisis de contenido sobre las características del sistema educativo y de la escuela como centro físico correspondiente a la Época Franquista.

En cuanto a la muestra, nuestro sujeto tiene 68 años, es jubilado, cuenta con estudios primarios, nació y vive en Zújar, un municipio de la parte noroccidental de la comarca de Baza de la provincia de Granada. La realización de la entrevista nos aportó un importante material acerca de las experiencias educativas vividas así como la explicación de las diferentes características de la escuela durante la Época Franquista en este pequeño pueblo.

\section{Resultados de la entrevista realizada}

\section{Datos relacionados con la infancia}

Cuéntame lo más significativo sobre tu infancia

El pueblo estaba muy poblado antes de empezar la gente a irse a Barcelona porque entonces la gente ya empezó a emigrar a Barcelona cuando la industria de Barcelona y entonces nos juntábamos a jugar en la plaza mayor. Jugábamos a Higos.

¿Cómo era el juego de a higos?

Hacíamos como en las plazas de toros donde están las barreras pues lo mismo, haciamos cinco o seis sitios donde saliamos y entonces había veinte que estábamos puestos para irnos de un punto a otro, de otro a otro y entonces al salir por las otras empezaban si te pillaban decían higos, si no te pillaban pues pasábamos cuantas más veces nos moviamos, pues ganábamos, si no pues perdiamos.

¿Podrías describir la vestimenta que normalmente utilizaban los niños y las niñas?

Entonces los niños gastaban pantalones cortos, todos con pantalones cortos hasta ya grandes con catorce o quince 
años todavía usaban pantalones cortos, y las niñas pues llevaban unos vestidos poco largos.

¿Había distinción de ropa entre unos niños y otros?

Si había mucha distinción de clase entonces.

¿Usabas uniforme en el colegio?

No, con la misma ropa que llevábamos entrabamos y alli lo único que tenías era un guardarropa con Don Antonio Vilchez el maestro.

¿Y la alimentación que tenías, que comías tú normalmente en un día?

Pues la alimentación también estaba con mucha distinción de clase, yo todavía me acuerdo de niños que pasaban hambre...

¿Mucha hambre?

Sí, nosotros estábamos un poquillo mejor, dentro que no había ni yogurt ni cosas de estas nuevas como ahora, comíamos mucha cosa caliente, garbanzos y cosas de cuchara, potajes... pero en fin comíamos.

\section{Contexto y relaciones dentro de la familia}

¿Cuánto miembros componen tu familia?

Pues yo tuve la suerte que estábamos muy pocos, estábamos nada más que mi hermana y yo. Pues yo casi que me crie como si hubiera estado solo, porque como se murió mi abuelo y mi hermana, no sé si tendría ocho o nueve años, porque yo tenía seis y ella me lleva tres, y entonces se subía alli a que mi abuela Lola a dormir para darle compañia de noche y entonces pues yo estaba generalmente solo, y hacía mis deberes solo y siempre dormía solo de noche.

¿Qué estudios tenían tus padres y en qué trabajaban?

Pues estudios dentro de lo que cabe de la posibilidad que había mucha gente que era analfabeta, pues mi padre y mi madre tenían sus conocimientos y escribian muy bien y seguían las cuatro reglas, hacian cuentas.

¿En qué trabajaban?

Pues trabajábamos porque teníamos un... en la agricultura y teníamos una tienda, mi padre se iba a trabajar con gente que buscábamos y mi madre pues se quedaba en la tienda, otras veces se quedaba mi padre, en los dias de lluvia y cuando no se iba a trabajar al campo.

¿La tienda de qué era?

De comestibles.

¿Dónde vivías en la época en la que realizaste tus estudios?

Vivía en el pueblo bajo, a donde más... porque en el pueblo había casas y cuevas, abajo estaban las casas y arriba había unas cuevas que las construyeron los moros y había unos barrios de cuevas y ahí era donde vivía generalmente la gente más pobre, eran como los trabajadores que trabajaban para la gente que estaba abajo que tenía sus tierras y demás.

¿Hablaban tus padres con el maestro para ver cuál era tu progreso en la escuela?

Sí, teníamos un maestro que tenía una disciplina muy grande, porque yo cuando estuve en la mili pues la disciplina que había en la mili no tenía ni comparación con la que tuve en la escuela con el maestro este, que le decian Don Antonio Vilchez, no Álvarez, "Vilches" es este del que hemos estado hablando antes.

¿Cómo era la relación con tus padres y hermanos? ¿Tenían en cuenta la opinión que tú les dabas?

Sí, yo hablaba mucho con mi padre y eso, mi padre estaba con la baba caída, yo hablaba con mi padre y mi madre, teníamos unos conocimientos muy buenos, de por sí me ha servido para todos los "siempres" amén, para luego para toda mi vida.

¿Tenían tus padres interés y preocupación por la educación impartida hacia ti?

Si claro, porque antes no pasaba como ahora, el maestro si no llevabas las cosas bien y los padres pues no subian a quejarse, sin embargo ahora no puedes mirar a los zagales ni siquiera están ya las madres que a mi niño no hay quien le pegue, que a mi niño no hay quien le falte y tal, y generalmente pues hay... dentro de lo malo porque lo peor es que hay zagales que salen de la escuela casi igual que entran.

\section{3.- Características del maestro}

¿Cómo era el maestro que te dio clase?

Bueno, en primer lugar teníais que ir muy limpio, lavado y la ropa aunque fuera de poca tijera pero por lo menos tenía que ir lavada y limpia, cuando estábamos nos ponía en dos filas y nos miraba uno a uno, que ibas con las manos sucias o sin peinar te mandaba alli a un caño que había y alli tenías que lavarte con un estropajo y jabón, eso era para empezar y luego ya se empezaba y cuando estaba a los dos meses de estar en el curso teníamos que saber la lección, habríamos el libro y la pregunta que tocara nos ponía en dos filas uno en frente de otro, porque había las bancas y había pasillos vacíos a los lados entonces nos ponía de pie y habría el libro y entonces o preguntaba los verbos y eso y nos preguntábamos los unos a los otros, primero preguntaba a una fila, la otra fila respondía cuando terminaba al revés o viceversa, preguntaba la otra. 
¿Era muy mayor?

No, aquel hombre tendría unos cuarenta años si acaso.

¿Su vestimenta, su edad... cómo era?

Aquel hombre era muy limpio y no se untaba, iba siempre limpio para dar ejemplo, pero dentro de eso era un buen maestro en el sentido que si tú veías que era ordenado y limpio y si hacías todas tus cosas lo llevabas todo bien, los deberes y demás, pues era muy amigo del que trabajaba, en fin, en resumías cuentas él no quería vagos, los vagos lo pasaban muy mal, porque los ponía alli al lado de él, en la mesa de adelante y tenía cada media hora le preguntaba la lección y si no se lo sabias pues desde luego aquello era una pena, por partes se pasaba porque le daba algunos unas palizas que por partes aquello era una pena.

\section{Horario de la jornada lectiva}

¿A qué hora te levantabas para ir al colegio?

Pues no me tenía que llamar mi madre, porque tal miedo que teníamos todos los zagales que aquello era el terror, yo no me acostaba de noche hasta que no hacía los deberes me quedaba muchas noches dormido, alli en la mesa camilla y mi madre me despertaba, y me decía: "¿has terminado ya?". A veces le decía "sí", pero otras no los terminaba porque me agotaba desde por la mañana y hasta por la tarde, porque teniamos escuela por la mañana y por la tarde, no librábamos nada más que el jueves por la tarde, los sábados también, no se libraba nada más que el domingo, de hecho hay compañeros míos de la escuela que se pasaron a la guardia civil o a la policía y a la armada y eso, y yo he hablado con ellos y le he preguntado ¿qué tal el examen?, que si han tenido problemas con el examen, y me han dicho que no que eso había sido pan comido, porque como iban formados de aquel maestro pues han hecho todos, muchos han tenido buenos puestos.

¿A qué hora empezabas las clases y a qué hora terminabas?

De nueve a una y de tres a cinco.

¿Los sábados también?

Toda la semana excepto el jueves por la tarde.

¿Y explícame un poco el orden del desarrollo de un día, de una clase normal?

Pues alli llevábamos cada día teníamos una asignatura, tocaba lunes por decir Geografía, martes Matemáticas, miércoles Aritmética, los jueves teníamos Religión porque entonces la Religión estaba, se puede decir en moda, en fin teníamos cada semana teníamos una asignatura y eso había que llevarlo a la perfección. Los zagales que destacaban, porque siempre había diez o doce que eran más inteligentes pues todos los domingos el maestro les daba una entrada, un aval para que fueran al cine, porque entonces el cine estaba muy en moda el cine, e iban y le pagaban una entrada para que fueran al cine asi era para que los otros zagales les diera envidia y apretaran también.

¿Existían los recreos?

Sí nos daba media horilla de doce a doce y media.

¿Normalmente se comía en casa o en el colegio?

No, en el colegio no se comía nada, en el colegio no había nada más que disciplina y trabajo.

¿Cómo era el horario de la escuela cansado, aburrido, entretenido, gratificante, fatigoso?

Algunas veces se veía uno fatigoso porque si subías con la lección que a lo mejor no la tenías muy clara, pues no hacías nada más que pensar qué me pasará a mi hoy porque ya habias visto el resultado del que estuvo ayer que no la tenía muy clara, entonces teníamos alli un espiritu de miedo, de terror.

¿En cuanto a las fiestas anuales o religiosas, políticas y locales, teníais que asistir a la escuela o teníais el día libre?

Pues como no fuera una cosa muy cercana como una boda de un hermano o alguna cosa de esas, tenías que pedir permiso y contárselo z por $b$, y si te daba pero el rato que... un tal... un muchacho de allí pues le dijo Don Antonio mañana yo no voy a ir a la escuela y le dijo pues que pasa para eso y le dijo que se casa mi hermano y dije pues muy bien, dice ¿a qué hora se casa tu hermano? Y le dijo, pues a las doce, y dice pues entonces no pasa nada, tú te vienes por aquí, bajas antes porque de aqui a las doce ¿qué vas a hacer tú en tu casa ganduleando? y tú sabes que aqui en el colegio no existe la pereza, pues luego me lo recuerdas media hora antes y ya te vas, pero el niño se supo de listo y dijo: este a lo mejor no se acuerda y entonces ¿qué hizo? no ir, pero sí se acordó, mandó a cuatro zagales diciéndole que lo esperaba el maestro alli en la clase y entonces fue y no le dio muy buenas memorias y lo tuvo alli hasta las once y media, media hora antes de la boda lo dejó que se fuera, asi es que aquel maestro no dejaba pasar ni una ni ninguna, prueba esta que todos los niños que hemos desfilado por su clase hemos sido el modelo y el ejemplo, porque salimos preparados cien por cien de todas las cosas en educación, saber comportarnos y saber también y saber de esto que lo que había antes en las escuelas.

¿Se controlaba de alguna forma la no asistencia al colegio?

Claro, porque es que alli pasaban lista todas las mañanas, el maestro pasaba lista todas las mañanas, además el maestro ya sabía quién faltaba porque como cada uno tenía su banca, se daba una vuelta y sabía si faltaban dos, uno, cinco, o no faltaba ninguno.

¿Los motivos principales por los que no se asistía a la escuela cuáles eran?

Pues la clase esta que estuvimos, que daba el tercer curso alli faltaban pocos, porque si faltabas es que iba a por ti ya 
cuando pasamos al cuarto curso que era ya un maestro más suave si faltaban algunos, eran más grandes y ya empezaban a ayudar a los padres y algunos que iban con una cabra, el otro que iba a por los concejos, el otro que le ayudaba a su padre a la aceituna, en fin ya tenían de trece a catorce años y en fin ya íbamos faltando algún día que otro porque este maestro era bueno y ya ese hombre no iba a buscarlos ni nada y ya se hacía el cargo de la situación que se encontraba la gente, porque esto que estamos hablando fue en el año, yo naci en el cuarenta y nueve, teníamos entonces seis o siete años, pues en el cuarenta y ocho o cincuenta y todo eso.

\section{Características de la escuela}

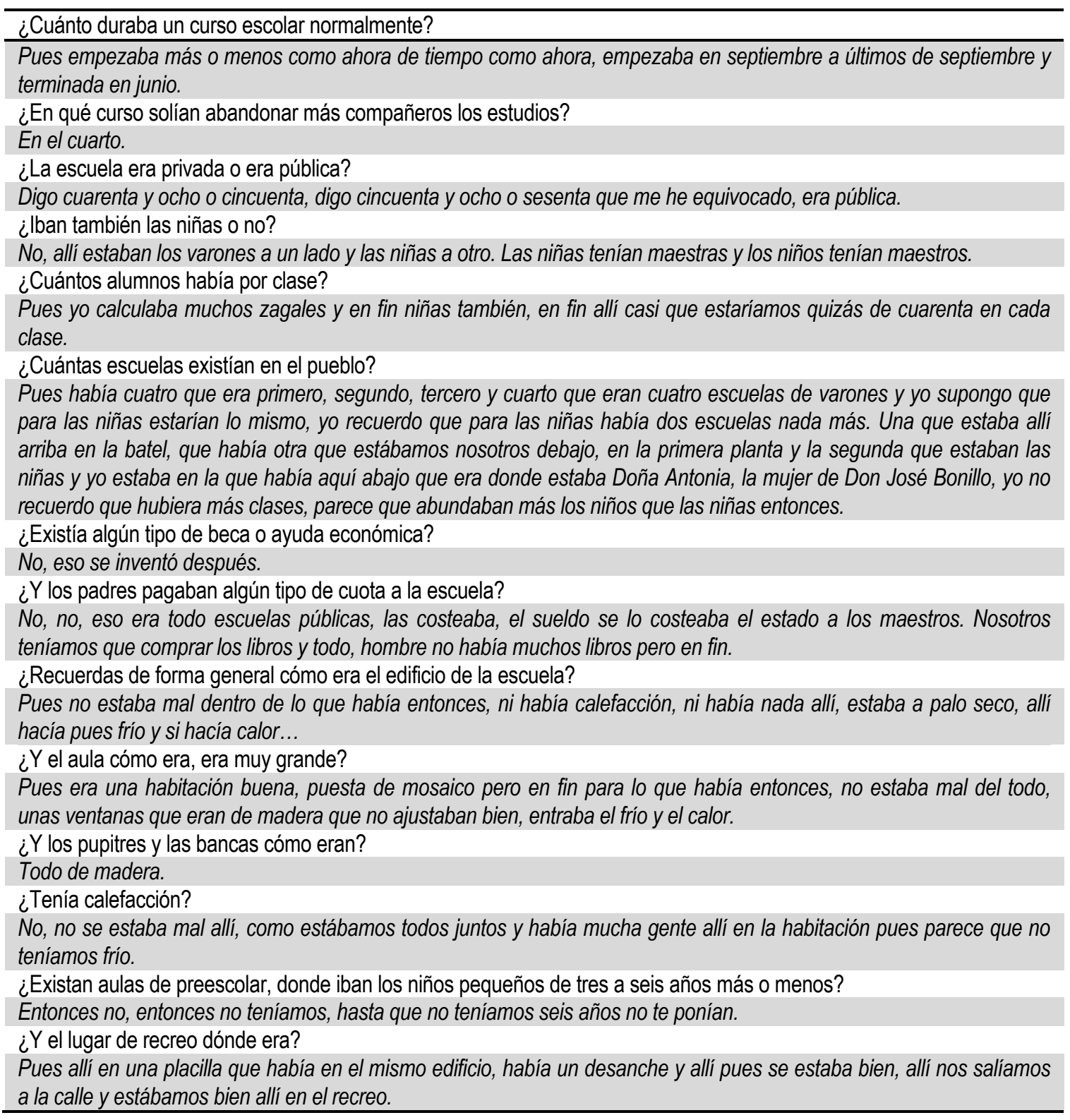

\section{Currículum y metodología}

¿A qué edad te iniciaste en la lectura y en la escritura?

Pues en el segundo curso, en el primero todo se volvía nada, alli pues veías las vocales la a, e, i, o, u y en fin una miajilla de... en el segundo curso ya se empezaba ya te iban apretando más y ya en el tercero empecé con el maestro este que estábamos hablando y ya te ponía al día.

¿Cuáles eran las primeras materias que se enseñaban en los primeros años de tu escolarización? ¿Las asignaturas?

Ah, todos los años aprendiamos la Religión, Matemáticas, la miajilla en fin en tercero era cuando ya te ponian bien puesto que ya llevabas Geografía, Aritmética, Matemáticas y Religión, Política no, porque entonces la política no existía, porque entrábamos entones en la dictadura. 


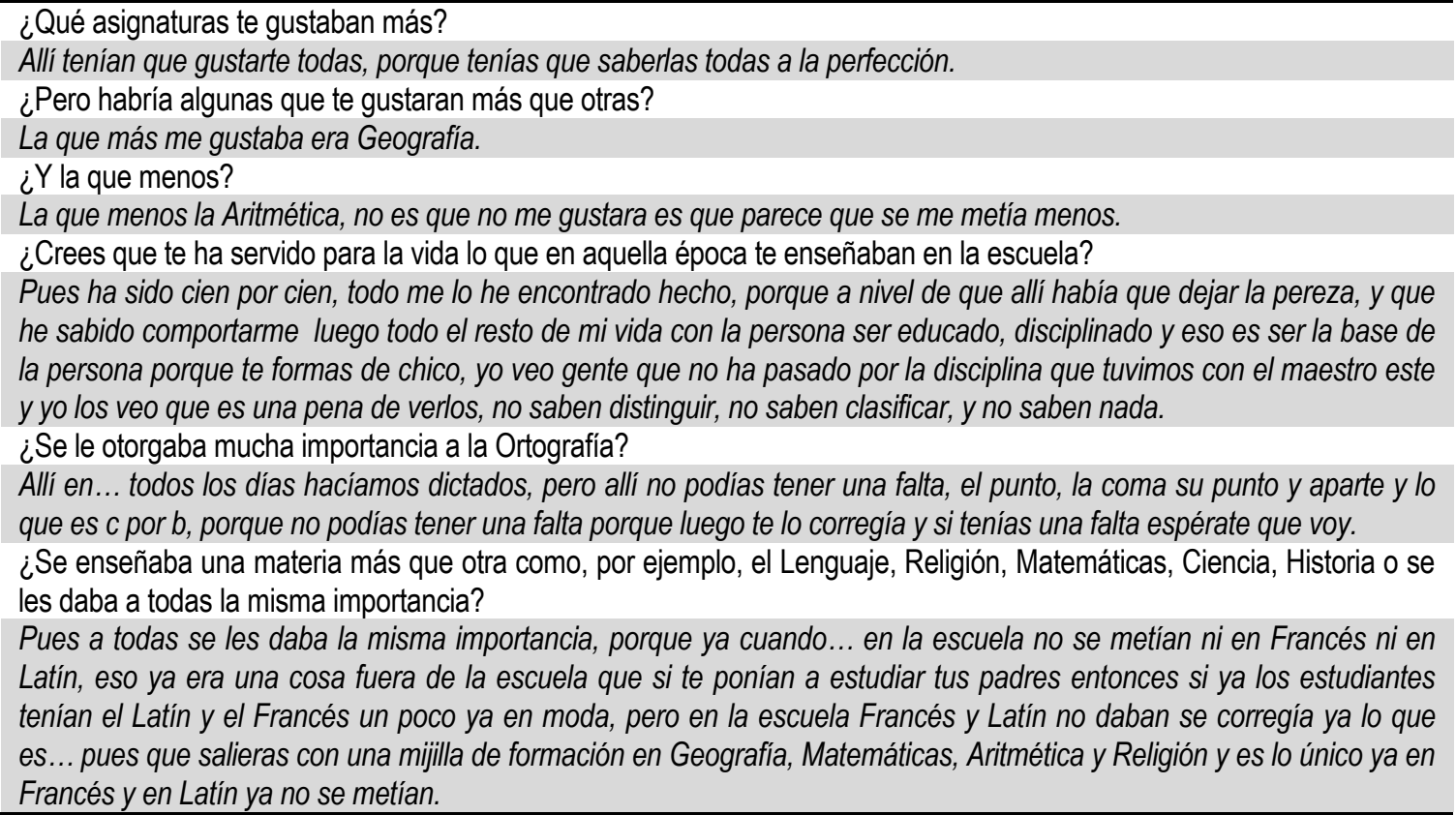

\section{Material didáctico y libros empleados}

¿Recuerdas que tipo de material didáctico había en el aula?

Muy poco, una vez me compró mi padre un bolígrafo de Baza que me lo trajo y el bolígrafo aquel le chocó hasta el maestro porque muchas veces se sentaba alli al lado de mi banca y me lo pedía algunas veces para escribir el algunas cosas.

¿Entonces el material de la escuela vuestro?

Sí.

¿Qué tipo de material utilizabais para escribir?

Pues alli comprábamos no había folios sueltos, libretas más grandes, más chicas con sus renglones, las hojas y eso es lo que llevábamos.

¿Con qué solías escribir, con el boli que me has contado antes?

Pues con el bolígrafo que me compró mi padre y con el lápiz también.

¿Existían cuadernos especiales para Cálculo, Matemáticas o fichas?

No, teníamos una libreta o teníamos dos libretas a donde sentábamos depende de lo que fuera.

¿Hacíais dibujos o manualidades?

Sí.

¿Qué material solíais utilizar?

Unos cuadrillo que había de papel pero sin renglones, para dibujar por cierto que yo para dibujo no se me daba bien he sido muy malo para dibujar, claro que el maestro este en eso no se metía cada uno dibujaba como quería y como podía en eso no era tan estricto como para lo demás.

¿Llevabais objetos de casa para la realización de tareas manuales?

Claro si aquel hombre no te dejaba vivir, ni de noche ni de día.

¿Por qué?

Porque de día tenías que estar bajo el mandato de él y de noche tenías que estar en tu casa haciendo los deberes que te echaba. Así que estabas siempre en la escuela como decía aquel, cuando estabas dentro y cuando estabas fuera.

¿Disponíais de mapas o películas o esferas terrestres en las clases de Geografía?

No, no teníamos nada más que dos mapas, con el mapa de España, los ríos y ya está.

¿Y en la clase de Naturales disponíais de material de laboratorio, esqueletos que os facilitasen la tarea? No.

¿Teníais clase de Música?

Eso ya se inventó después de yo estar en la escuela.

¿Y Gimnasia?

Gimnasia en las otras escuelas teníamos nosotros.

¿Y teníais algún material diferente para realizar las clases?

Un pito que tenía el maestro.

¿Y ya está?

Ya está todo, esto que decía esto que lo utilizaba para cuando alguno se estaba portando mal para que paraba y ya le 
decía parad....

¿El profesor utilizaba algún instrumento para avisar de las entradas y salidas tanto de clase como del recreo?

No, el decía a las once a las doce y media decía saliros un poco a la calle y jugáis un poco, y nos levantábamos y nos salíamos y luego por la ventana nos decía y daba dos palmas y de momento ya sabíamos lo que teníamos que hacer, de momento nos poníamos en fila, pegaos a la pared y ya íbamos entrando uno a uno sin voces, sin achuchones, sin alborotos, sin nada de nada.

¿Había algún material concreto que se usase por separado, los niños y las niñas?

No, porque las niñas yo no sé cómo andarían porque alli no había ninguna chiquilla, porque yo me compró mi padre una cartera de material y los zagales no hacían nada más que preguntarme, porque la mayoría de los zagales no llevaban nada más que unos roperos que era un cuadrillo de tela que iba abierto arriba y con un atadero para colgárselo por el hombro y alli pues llevaban todos sus libros, sus libretas, el borrador y todo eso.

¿Y los libros que leiais en clase eran comprados, o heredados?

Pues claro el que no tenía, se lo prestaba su primo, su amigo o su vecino, sí.

¿Había libros de consulta en el aula?

Alli había un armario que tenía el maestro algunos libros, pero casi que no teníamos nada, porque no teníamos tiempo para que nos dejara algún libro, para que lo viéramos ya teniamos bastante con lo que habia que hacer.

¿Había biblioteca?

La biblioteca ya fue más tarde, el ayuntamiento la puso más tarde en una habitación que tenía en la plaza y ya iban muchos niños alli a la biblioteca, pero eso ya fue mucho más después.

\section{Actividades extraescolares desarrolladas}

¿Qué actividades extraescolares se realizaban? ¿Me has descrito antes el juego del higo?

Ah y también jugar a doping.

¿Y eso cómo era?

Y eso era todo la ralla en la calle con un caballoncillo de tierra y entonces pues uno se acachaba y entonces conforme íbamos blincando todos en lo alto de él se iba corriendo un paso hasta que ya llegábamos cuatro pasos desde la raya que se pintaba blanca, y esa no se podía pisar si se pisaba ya tenías tú que acacharte y el otro se levantaba y entonces ya llegabas que había cuatro pasos y muchos que no estaban muy ágiles para blincar y entonces siempre les tocaba estar acachados, yo para ese juego era muy bueno porque blincaba hasta diez u once pasos.

¿En cuanto a los castigos y los premios, háblame de ellos dentro de la escuela?

Los castigos eran siempre casi los mismos, los más torpes llevaban siempre el gato al agua, había algunos que se inventaban, me acuerdo de alguno que cuando le preguntaba hacia con el pie asi y porque se las inventaba porque no sabía ya qué hacer, pero como aquel maestro no le miraba la cara a ninguno, pues se levantaba para ir a pegarles y le decía no pegue usted Don Antonio y bueno ves como hablas, se llamaba Cuerva.

¿Y los premios, cuáles eran los más usuales o no os daban ninguno?

Premios nada más que todos los domingos que repartía la entradas aquellas del cine.

¿Utilizaba otros procedimientos para motivar al alumnado?

No.

\section{Actividades del alumno}

¿Y los deberes, os mandaban muchos para casa?

Sí, muchos no los podías hacer y luego llegaban los madres mías alli en el maestro.

¿Cuánto tiempo solías emplear para la realización de tareas?

Pues depende, había veces que me dormía y luego mi madre me llamaba y tenía que terminarlas, luego otras veces las terminaba pronto, depende de lo que fuera que hacía si me gustaba tardaba poco pero si era Aritmética y tal más dudosa.

¿Te ayudaban?

No, algunas veces mi padre, cuando era chico, si tenía que ponerme muestra me ponía muestra él, pero ya con Don Antonio no, tenías que desarrollarlo tú solo allí.

¿Eso lo haciais fuera del horario escolar?

Claro.

¿Y las actividades de los alumnos eran preferentemente grupales o individuales?

No, no, alli la lección que se daba era para todos y allí cada uno tenía que sacar fruto, tú tenías que estudiártela en tu casa y tenías que hacer un examen por escrito y él te lo corregía si estaba bien te daba un cinco, no solía dar mucho, cinco, seis y si no estaba bien te daba un dos o tres o un cero.

¿Tenías otras obligaciones aparte de hacer la tarea como limpiar la pizarra, o la clase, regar las macetas ir a por tizas? No, no, aquel hombre como contaban de otros colegios que iban los alumnos a por los conejos que tenían conejos los 
alumnos este maestro no nos mandaba nada de nada más que al trabajo, pero el trabajo de allí para aprender para formarte de por si luego fue de aqui que le hicieron alcalde y como a él no le gustaba pidió traslado y se fue, luego a los diez o doce años vino en unas fiestas y nos agrupamos alli y nos decíamos que ha venido Don Antonio que si quieres verlo y tal y entonces íbamos a un bar que le decían el "bar de Lindes" que era alli una especie de una taberna y alli nos agrupamos un montón y alli ya que éramos hombres teníamos veinte años, otros habíamos salido de la mili, otros se iban a la mili y en fin me acuerdo que nos invitó alli a lo que queríamos, uno a una cerveza, el otro a una fanta, en fin y ya pues no nos pegó a ninguno estaba alli en plan amistoso y ya pues ya nos iba preguntando cómo te iba a ti hoy Don Antonio, he echado las oposiciones a la policia ¿tú qué tal te ha ido? pues ya ves, y le echaban las manos por el hombro que mira que aquellos ratos vosotros os creíais que eran tan malos y mira que bien os ha venido, y el otro pues ha hecho el oficio tal pero gracias a la disciplina de aquel hombre.

\section{Método de evaluación}

¿Había exámenes?

Claro, al final de curso nos hacía una redacción para ponernos en el libro ya sabes que había.

¿Cómo era el sistema de calificaciones?

Pues ya has visto muy bajo cinco, seis, siete... eso como ahora que yo veo que me han dado un nueve, un diez, un ocho... y yo lo veo eso muy fuerte.

¿Y los exámenes cómo eran?

Los exámenes pues nos iba preguntando alli o nos ponía una redacción y teníamos que hacerlo, y ya él los corregía y según te portabas asi te ponía un no acto, acto eso era al final de curso.

¿Era necesario aprobar para pasar al final de curso?

Claro, si no aprobabas pues te dejaba otra vez alli, me acuerdo de un primo mío que tenía un año menos que yo y el primo de mamá también que eran del mismo tiempo, y estaban alli en la primera banca y ya pues para probarlos les decía pues ya los que quieran pasar a cuarto curso que se levanten que hacen falta veinte que tienen que pasar a cuarto curso, como tanto miedo le teníamos, tanto terror llegábamos uuuu algunos que no eran inteligentes y estaban a gusto con él, pero los que eran más torpecillos y más perezosos de momento se levantaban pero claro aquel maestro era más listo y llegaba e iba preguntándote ¿Antonio es que no estás a gusto conmigo? Y claro como le decias que no pues claro, si te decía anda siéntate si "mas" dicho que si estas a gusto como te vas a ir, claro él los clasificaba y podías pasar y los que no podian pasar y les decian anda siéntate y estate un año más si dices que estás a gusto para qué te vas a ir. Luego ya sabíamos alli los zagales hablábamos alli y decíamos cucha que he tenido la posibilidad de irme ya y me ha dicho que me quede.

¿Entonces la nota influía en la posición dentro de clase?

Pues claro, la nota y el que sabía de cada uno del lao que renqueábamos y luego la nota no la cogía y luego la cogía él y te decía vete porque sabía a qué te podías ir, pues a la venga ya te puedes ir, coge tu cartera y todo lo que tengas y vete con Don Juan Oliver, que era el maestro de cuarto curso, el que veía que estaba entre Gor y Gorafe pues le decía es que no estás a gusto conmigo, entonces si estas a gusto conmigo siéntate para qué te vas a ir y claro allí nos escogía todos los años depende de los que se iban con Don Juan unos años quince, otros veinte, diez, veinticinco... y asi lo hacía.

¿Los alumnos podían revisar los exámenes?

¿Revisarlos en qué sentido?

¿Podías revisar un examen cuando te daban la nota?

No, no te decía nada, te enseñaba el librillo y te ponía Apto o No Apto y ya está.

¿El inspector veía los exámenes para ver cómo avanzaba el curso?

No eso ya no te puedo yo decir, porque era al final de curso ya no sé yo si los veía a la entrada del curso otra vez, en septiembre pero eso yo ya no lo veía nunca.

¿Crees que la asistencia a la escuela estaba condicionada por el nivel económico de cada familia?

Pues alli nos trataba a todos iguales, alli no había distinción alli estábamos cuarenta y alli todos éramos iguales.

¿A la hora de asistir a la escuela?

Nada alli faltabas e iba a por ti, lo mismo fueras rico que pobre aquel hombre si estabas alli no te decía nada, una vez fue una hermana de uno y le dijo que mientras que no le dijera los verbos que no se iba y la hermana fue a llevarle un poco pan y chorizo a los hermanos que tendrían ocho o diez años, y el maestro pues era muy listo como vivía alli en la casa detrás de la escuela alli en lo de la misma casa pues se ponía en la ventana y había unas escaleras de donde se subía a la escuela y la vio venir y entonces se asomó a la ventana y le dijo no hay comida hasta que no se aprendan la lección porque tus hermanos son unos gamberros así que hasta que no se aprendan la clase no hay comida, y por donde has venido te vas, y la mujer tuvo que agachar las orejas y se fue y los tuvo alli todo el santo día sin probar ni agua.

Bueno por último me quieres contar algo significativo de tu periodo escolar y que no haya aparecido en la entrevista que te hecho.

Pues yo veo ahora el blandeo que hay en las escuelas que no está en consonancia con lo que había antes, se ve que a 
nosotros nos tocó vivir la vida mala después de la guerra en la posguerra, donde no podías hablar nada ni decir nada ni nada de nada, no existían reclamaciones ni nada de nada, solo trabajo y disciplina y pocas posibilidades con un lápiz, dos libretas y un roperillo.

\section{Conclusiones}

Con la información obtenida sobre todo en la primera parte de la entrevista hemos podido conocer la gran carencia económica y educativa derivada de la situación posbélica y de sus posteriores consecuencias. Del mismo modo, la educación impartida y las grandes diferencias existentes, tanto en la vida cotidiana, como en la escolarización de dicha época, compartiendo con nuestro entrevistado momentos muy íntimos regalándonos la posibilidad de conocer elementos muy personales de momentos vividos junto a familiares y amigos.

De manera específica, tras el análisis de la entrevista destacamos principalmente dichos aspectos que nos han ayudado a conocer las características del sistema educativo y de la escuela como centro físico durante esta época, así como averiguar que la asistencia a la escuela estaba condicionada por el nivel económico de las familias.

- El currículum de las niñas era muy diferente al de los niños. La gran diferencia existente se encuentra en la asignatura de labores para ellas donde se les enseñaba a bordar y cocinar. Del mismo modo, el uso de uniforme en las niñas y ropa de calle en los niños.

- Uso único de una enciclopedia para impartir todas las asignaturas de cada curso.

- Existencia de una pequeña libreta para todos, junto con una pizarra para poder escribir lo explicado por el maestro y los trabajos a realizar en clase.

- El absentismo producido por la necesidad de ayudar en casa, siendo muy usual en cursos más avanzados, llegando a abandonar el colegio para ponerse a trabajar. Éste dependía del nivel económico familiar.

El poder realizar esta investigación ha supuesto una enorme satisfacción ya que todos los objetivos planteados inicialmente se han conseguido, así como poder conocer las situaciones vividas en la escuela, y aspectos muy profundos de la Guerra Civil sobre todo de la posguerra suponiendo para nosotros una gran satisfacción creando estrechos lazos junto a nuestros entrevistados dando voz a una vida llena de dificultades.

Como profesionales de la educación destacamos la necesidad de educar bajo los parámetros de un pensamiento crítico, subrayando la necesidad e importancia de este pensamiento como la principal herramienta necesaria para afrontar la ideología dominante enmascarada dentro de nuestras escuelas.

Referencias

Cuadernos de Historia de la Educación N01, (2002). RECURSOS DIDÁCTICOS. HISTORIA ORAL Y MUSEOS PEDAGÓGICOS. Sevilla: Sociedad Española de Historia de la Educación.

Egido-León, Á. (2001). Trabajando con la memoria: exilio y fuente oral. Historia y Comunicación Social, (6), 265-279.

Escolano-Benítez, A. y Hernández-Díaz, J. M. (2002). La memoria y el deseo. Cultura de la escuela y educación deseada. Valencia: Tirant Lo Blanch. 
Folguera-Crespo, P. (1994). Cómo se hace historia oral. Madrid: Eudema.

López, F. \& Pozo, T. (coords.) (2002). Investigar en EDUCACIÓN SOCIAL. Sevilla: Los Remedios.

Lucena-Ferrero, R. (1999). Historia de la educación en la España Contemporánea. Editorial: Madrid: Acento.

Puelles-Benítez, M. (1980). Educación ideológica en la España contemporánea. Barcelona: Editorial Labor.

Puelles-Benítez, M. (2008). Modernidad, republicanismo y democracia: una historia de la educación en España. Valencia: Tirant lo Blanch.

Rabazas-Romero, T. \& Ramos-Zamora, S. (2006). La construcción el género en el franquismo y los discursos educativos de la Sección Femenina. Encounters on Education, (7), 43-70.

Ruiz-Olabuenaga, J.I. (2012). Metodología de la investigación cualitativa. Bilbao: Universidad de Deusto.

Sánchez-Redondo-Morcillo, C. (2004). Leer en la escuela durante el franquismo. Cuenca: Ediciones de la universidad de Castilla-la Mancha.

Sonlleva-Velasco, M. \& Torrego, L.M. (2014). La Escuela Primaria del primer franquismo desde las voces del alumnado segoviano: una iniciación en la investigación educativa. Tendencias Pedagógicas, (24), 285- 306.

Suárez-Pazos, M. (2002). Historias de vida y fuente oral. Los recuerdos escolares. En A. Escolano Benito y J. M. Hernández Díaz (Ed.), La memoria y el deseo. Cultura de la escuela y educación deseada (pp. 429-443). Valencia: Tirant lo Blanch. 